\title{
Polyol-Mediated Synthesis of Zinc Oxide Nanorods and Nanocomposites with Poly(methyl methacrylate)
}

\author{
Alojz Anžlovar, ${ }^{1,2}$ Zorica Crnjak Orel, ${ }^{1,2}$ Ksenija Kogej, $^{3}$ and Majda Žigon ${ }^{1,2}$ \\ ${ }^{1}$ Center of Excellence for Polymer Materials and Technologies, Tehnološki Park 24, 1000 Ljubljana, Slovenia \\ ${ }^{2}$ Laboratory for Polymer Chemistry and Technology, National Institute of Chemistry, Hajdrihova 19, 1000 Ljubljana, Slovenia \\ ${ }^{3}$ Chair of Physical Chemistry, Faculty of Chemistry and Chemical Technology, University of Ljubljana, \\ Aškerčeva 5, 1000 Ljubljana, Slovenia
}

Correspondence should be addressed to Alojz Anžlovar, alojz.anzlovar@ki.si

Received 22 January 2012; Revised 7 April 2012; Accepted 10 April 2012

Academic Editor: Sevan P. Davtyan

Copyright () 2012 Alojz Anžlovar et al. This is an open access article distributed under the Creative Commons Attribution License, which permits unrestricted use, distribution, and reproduction in any medium, provided the original work is properly cited.

\begin{abstract}
$\mathrm{ZnO}$ nanorods (length $30-150 \mathrm{~nm}$ ) were synthesized in di(ethylene glycol) using $\mathrm{Zn}\left(\mathrm{CH}_{3} \mathrm{COO}\right)_{2}$ as a precursor and para-toluene sulphonic acid, p-TSA, as an end-capping agent. Increasing the concentration of p-TSA above $0.1 \mathrm{M}$ causes the reduction of the $\mathrm{ZnO}$ length. Nanocomposites with poly(methyl methacrylate) were prepared using unmodified nanorods. They enhanced the UV absorption of nanocomposites $(\sim 98 \%)$ at low $\mathrm{ZnO}$ concentrations (0.05-0.1 wt.\%), while visible light transparency was high. At concentrations of $1 \mathrm{wt} . \%$ and above, nanorods enhanced the thermal stability of nanocomposites. At low concentrations (0.05$0.1 \mathrm{wt} . \%)$, they increased the storage modulus of material and shifted $T_{g}$ towards higher temperatures as shown by dynamic mechanical analysis, DMA, while at higher concentrations (1.0 wt.\%) this effect was deteriorated. DMA also showed that spherical $\mathrm{ZnO}$ particles have a more pronounced effect on the storage modulus and $T_{g}$ than nanorods.
\end{abstract}

\section{Introduction}

Nanostructured materials constitute one of the most propulsive fields of materials, science and have received great attention due to their potential application $[1,2]$ in various fields such as electronics [3], microelectronics [4-6], sensors [7], photovoltaics [8, 9], electro-optical devices [10-12], and catalysis [13]. Zinc oxide $(\mathrm{ZnO})$ is an inorganic material with a large direct band gap $(3.34 \mathrm{eV})$, high exciton binding energy $(60 \mathrm{meV})$, high isoelectric point (9.5), and fast electron transfer kinetics as well as having a unique combination of properties $[14,15]$. All these features suggest the synthesis of special $\mathrm{ZnO}$ nanostructures and how to use these materials in novel unexplored applications. Nano $\mathrm{ZnO}$ can be synthesized in many forms: rods, wires, whiskers, belts, bipods, tetrapods, tubes, flowers, propellers, bridges, and cages [16-18]. A special field of nanomaterials is represented by extended and oriented nanostructures which are desirable for many applications [19].

One-dimensional $\mathrm{ZnO}$ nanostructures have been synthesized by many preparation techniques such as thermal evaporation, hydrothermal synthesis, metal organic chemical vapor deposition, spray pyrolysis, ion beam-assisted deposition, laser ablation, sputter deposition, template-assisted growth, chemical vapor deposition, sol-gel process, and solvothermal synthesis [20-22]. $\mathrm{ZnO}$ nanorods have been synthesized also by solvothermal reaction in various alcohols $[23,24]$.

A special type of solvothermal synthesis of $\mathrm{ZnO}$ is the polyol procedure which uses various diols as a reaction medium $[25,26]$. Besides acting as a reaction medium polyol also serves as a stabilizing agent and it reduces the particle growth [27-29]. The advantage of the polyol procedure is that it produces particles with an organophilic surface layer which needs no additional surface modification for the application in nanocomposites [30]. Combining the organic polymers with inorganic particles, fillers can result in materials with enhanced mechanical and other properties [31]. By reducing the size of filler the interface between the filler particles and the polymer matrix is substantially increased and therefore their impact on the properties of the composite is significantly enhanced $[32,33]$. Many polymer materials undergo chemical degradation when exposed to sunlight. Due to the thinner ozone layer and higher intensity of UV 
light, their degradation is becoming more intense and consequently their UV stabilization is of increased importance. Poly(methyl methacrylate), PMMA, is an amorphous thermoplastic material with exceptional optical properties. Due to favorable mechanical and processing properties, it replaces inorganic glass in many applications [30]. Despite intense research efforts, the development of a simple and effective method of preparation of homogeneous nanocomposites with PMMA matrix on both the laboratory and on the industrial scale is still a challenge. By combining the PMMA matrix and nano $\mathrm{ZnO}$, transparent materials with high UV absorption and improved thermal stability can be prepared.

In the present work we report on the synthesis of $\mathrm{ZnO}$ nanorods with organophilic surface at high concentration of the precursor $(1 \mathrm{M})$ by the polyol method, using di(ethylene glycol), DEG, as a medium and $p$-toluene sulphonic acid, p-TSA, as an end capping agent. The primary aim of our work was to demonstrate that homogeneous transparent PMMA/ZnO nanocomposites using unmodified $\mathrm{ZnO}$ nanorods, synthesized by the polyol method, can be prepared with potential application as UV stabilized PMMA materials with enhanced properties. UV stabilization using $\mathrm{ZnO}$ nanoparticles as $\mathrm{UV}$ absorbers represents an alternative to conventional UV stabilizers. The secondary aim was to determine the difference between the impacts of spherical $\mathrm{ZnO}$ particles and $\mathrm{ZnO}$ nanorods on the properties of PMMA/ZnO nanocomposites.

\section{Experimental}

2.1. Materials. The materials used are di(ethylene glycol), DEG (Merck, 99\%, for synthesis); Zinc(II) acetate monohydrate, $\mathrm{Zn}(\mathrm{Ac})_{2}$ (Sigma-Aldrich, 99\%, ACS reagent); $p$ toluenesulfonic acid monohydrate, p-TSA (Sigma-Aldrich, 98.5\%, ACS reagent); methyl methacrylate, MMA (technical); 1,1-Azobis(1-cyclohexanecarbonitrile), AICN (Aldrich, 98\%); and ethanol (technical).

2.2. Synthesis of $\mathrm{ZnO}$ Nanorods. $\mathrm{Zinc}(\mathrm{II})$ acetate $(1.0 \mathrm{M})$, pTSA $(0.1 \mathrm{M})$, and deionised water $(2$ mole/ 1 mole $\mathrm{Zn})$ were mixed with $60 \mathrm{~mL}$ of DEG and sonicated for $10 \mathrm{~min}$. The mixture was transferred into a $250 \mathrm{~mL}$ glass reactor equipped with a mixer, condenser, and digital thermometer. The temperature and color changes of the reaction medium were monitored over time. The temperature was raised over about $10 \mathrm{~min}$ to $190^{\circ} \mathrm{C}$ and kept constant for $50 \mathrm{~min}$ with constant stirring. Between $90^{\circ} \mathrm{C}$ and $120^{\circ} \mathrm{C} \mathrm{Zn}(\mathrm{Ac})_{2}$ dissolved in the DEG, after 20 to 30 minutes at $190^{\circ} \mathrm{C}$ the solution became white, and after $60 \mathrm{~min}$ a white suspension of $\mathrm{ZnO}$ was obtained. The suspension was left overnight and centrifuged ( $8000 \mathrm{rpm}, 20 \mathrm{~min}$ ). The $\mathrm{ZnO}$ was washed twice with ethanol and centrifuged $(8000 \mathrm{rpm}, 20 \mathrm{~min}$.). The obtained $\mathrm{ZnO}$ powder was left to air dry. Spherical $\mathrm{ZnO}$ nanoparticles were synthesized by the same procedure in ethylene glycol (size $20-40 \mathrm{~nm}$ ) and in 1,2-propane diol (size 30-50 nm) [34].

2.3. Synthesis of ZnO/PMMA Nanocomposites. Nanocomposites of the synthesized $\mathrm{ZnO}$ nanorods and PMMA matrix were prepared by the radical chain polymerization of MMA monomer in bulk in three variations: radical polymerization between glass plates starting directly from the $\mathrm{ZnO}$ dispersion in monomer (MMA) (procedure A), polymerization between glass plates starting from the previously prepared dispersion of $\mathrm{ZnO}$ in prepolymer (procedure $\mathrm{B}$ ), and polymerization between two glass plates starting from $\mathrm{ZnO}$ dispersion in prepolymer which was polymerized during constant sonication (procedure C). The detailed description of all three procedures is given in the previous publication [34]. The nanocomposite plate thickness using procedure A was $1.5 \mathrm{~mm}$, while procedures $\mathrm{B}$ and $\mathrm{C}$ gave nanocomposite plates with a thickness of $3.5 \mathrm{~mm}$.

2.4. Characterization Methods. The morphology of the synthesized $\mathrm{ZnO}$ nanorods was studied by SEM (Zeiss Supra $35 \mathrm{VP}$, acceleration voltage -3.37 or $5.0 \mathrm{kV}$, working distance, 3-6 mm, gold-sputtered samples) and HR TEM electron microscopy (JEM 2000FX microscope, JEOL, acceleration voltage $-200 \mathrm{kV}$ ). For HR TEM microscopy, $\mathrm{ZnO}$ nanorods were dispersed in an organic solvent. A drop of dispersion was placed on a Cu grid and left to evaporate the solvent. The nanocomposite materials were studied by STEM microscopy (Supra $35 \mathrm{VP}$, Zeiss, acceleration voltage $-20.0 \mathrm{kV}$, working distance $-4.5-5 \mathrm{~mm}$, STEM detector, ultramicrotomed sections). Nanocomposites were sectioned on the ultramicrotome (Leica Ultracut, Leica, thickness 80-250 nm).

The sizes of $\mathrm{ZnO}$ nanorods and their aggregates in MMA were measured by dynamic light scattering (3D-DLS-SLS spectrometer, LS Instruments equipped with $20 \mathrm{mV} \mathrm{He}$ Ne laser-Uniphase JDL 1145, P, wavelength $632.8 \mathrm{~nm}$ ). Scattering was measured at an angle of $90^{\circ}$. Samples in scattering cells were immersed in a thermostated bath at $20^{\circ} \mathrm{C}$, and ten measurements of $60 \mathrm{~s}$ were recorded for each sample and averaged afterwards. The translational diffusion coefficient, $D$, was determined while the hydrodynamic radius, $R_{h}$, was calculated from $D$ using the Stokes-Einstein equation (viscosity of MMA, $\eta=0.6 \mathrm{cP}$ at $20^{\circ} \mathrm{C}$ ).

UV-Vis spectra of nanocomposites were measured on an Agilent 8453 UV-Vis spectrometer, Agilent Technologies, (spectral range 290-380 $\mathrm{nm}$, sample width $12 \mathrm{~mm}$, thickness 1.6 and $3.5 \mathrm{~mm}$ ).

The chemical composition of $\mathrm{ZnO}$ nanorods was studied by FTIR spectroscopy using an FTIR spectrometer (Spectrum One, Perkin Elmer, spectral range $400-4000 \mathrm{~cm}^{-1}$, spectral resolution $4 \mathrm{~cm}^{-1}$, transmittance mode, $\mathrm{KBr}$ pellets).

Thermal properties of PMMA/ZnO nanorod composites were studied by TGA (STA 409, Netsch, temperature range $50-600^{\circ} \mathrm{C}$, heating rate $1^{\circ} \mathrm{C} / \mathrm{min}$, air flux of $100 \mathrm{~mL} / \mathrm{min}$, sample quantity $\sim 50 \mathrm{mg}$ ).

Crystalline fractions of nano- $\mathrm{ZnO}$ were characterized by XRD diffraction (D-5000 diffractometer, Siemens, $\mathrm{Cu}$ anode as the X-ray source, $25^{\circ} \mathrm{C}, 2 \Theta$ range $2-90^{\circ}$, step $0.04^{\circ}$, step time $1 \mathrm{~s})$. Crystallite sizes were calculated using the Scherrer formula.

DMA measurements were performed on DMA Q800, Thermal Analysis, using a single cantilever clamp (temperature range $30-150^{\circ} \mathrm{C}$, heating rate $5^{\circ} \mathrm{C} / \mathrm{min}$, amplitude $15 \mu \mathrm{m}$, frequency $10 \mathrm{~Hz}$ ). 


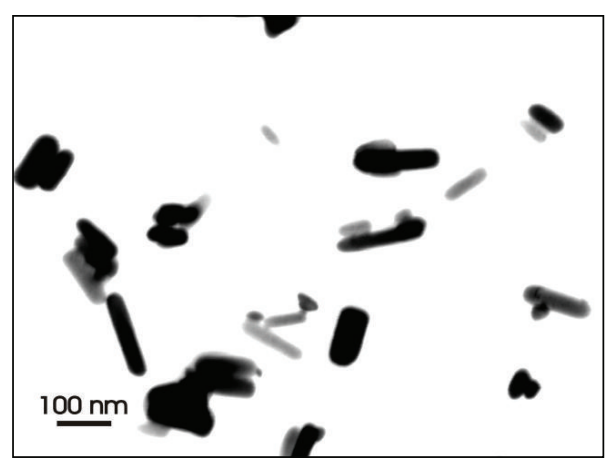

(a)

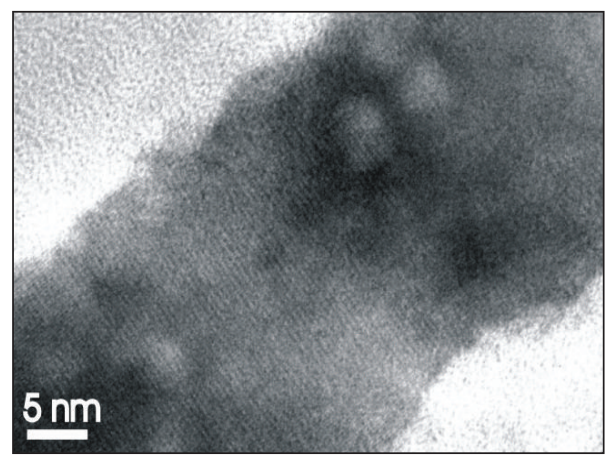

(c)

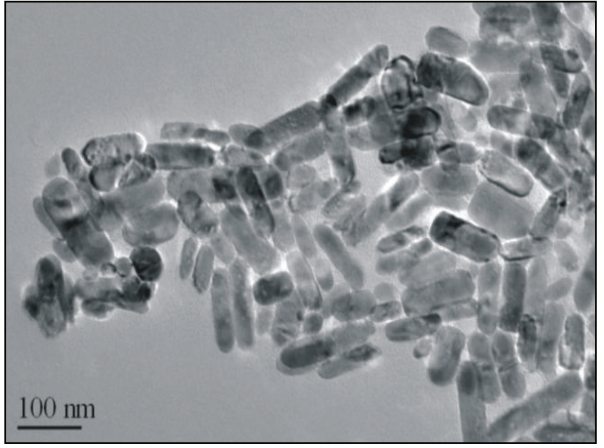

(b)

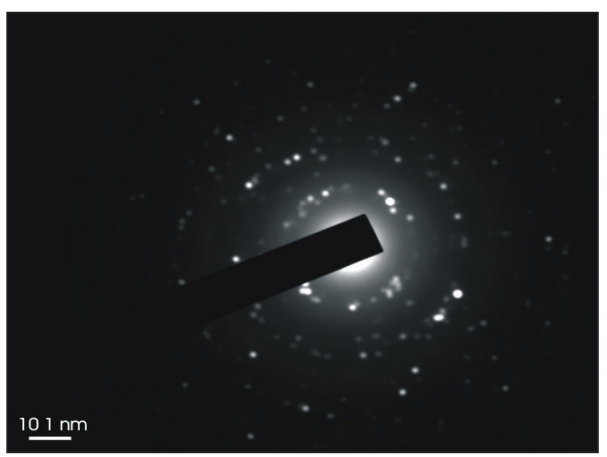

(d)

Figure 1: (a) STEM micrograph, (b) and (c) HR-TEM micrographs of ZnO nanorods, and (d) electron diffraction pattern of ZnO nanorods.

\section{Results and Discussion}

$\mathrm{ZnO}$ nanorods were synthesized by the hydrolysis of $\mathrm{Zn}$ (II) acetate in DEG with p-TSA as the end-capping agent, while in other diols predominantly spherical $\mathrm{ZnO}$ particles were produced. STEM and HR TEM micrographs (Figures 1(a) and $1(\mathrm{~b})$ ) show $\mathrm{ZnO}$ particles in the form of nanorods (diameter $10-50 \mathrm{~nm}$, length $30-150 \mathrm{~nm}$ ) with narrow particle size distribution. The HR TEM micrograph in Figure 1(c) shows characteristic crystallite fringes confirming that nanorods are highly crystalline.

The XRD diffractogram (Figure 2(a)(A)) shows characteristic $\mathrm{ZnO}$ diffraction maxima at $2 \Theta$ values of $31.8,34.5$, $36.2,47.6,56.6,62.9,66.4,67.9,69.1,72.6$, and 76.9 [35]. Calculated crystallite size using the Scherrer equation [36] is $45 \mathrm{~nm}$. Compared to the XRD diffractogram of spherical $\mathrm{ZnO}$ nanoparticles (Figure 2(a)(B)) it shows higher intensity of (002) peak, indicating the preferential growth of wurtzite rods along (002) direction (c-axis) $[8,18,24,37,38]$. The preferential growth in one direction is the consequence of the growth rate difference in various directions of the $\mathrm{ZnO}$ crystal. It is reported that during hydrothermal synthesis the relative growth of (0001) face is higher than that of other ones, leading to the formation of extended prismatic hexagonal $\mathrm{ZnO}$ crystals [39]. Nanorod growth is, as reported, caused by the adsorption of DEG molecules to the nonpolar faces of the crystal, while highly polar (0001) faces at both ends are able to develop and grow faster resulting in the formation of $\mathrm{ZnO}$ nanorods [40]. This explains why $\mathrm{ZnO}$ nanorods are formed only in DEG, while in other diols $\mathrm{ZnO}$ with regular morphology is formed [34]. The crystallinity of $\mathrm{ZnO}$ nanorods was additionally confirmed by HR TEM microscopy where characteristic fringes of crystallites were observed (Figure $1(\mathrm{c})$ ). The electron diffraction pattern (Figure $1(\mathrm{~d})$ ) confirms that synthesized $\mathrm{ZnO}$ nanorods are polycrystalline. By increasing the concentration of p-TSA from 0.1 to $0.4 \mathrm{M}$ the length of $\mathrm{ZnO}$ nanorods was reduced, indicating its important role in the mechanism of $\mathrm{ZnO}$ particle formation (Table 1).

The IR spectrum of $\mathrm{ZnO}$ usually shows a characteristic absorption band between 420 and $510 \mathrm{~cm}^{-1}$ due to two transverse optical stretching modes of $\mathrm{ZnO}$ [41]. In the case of $\mathrm{ZnO}$ nanorods this maximum is split into two maxima, one at 507 and the second one at $423 \mathrm{~cm}^{-1}$ (Figure 2(b)(A)), while spherical $\mathrm{ZnO}$ nanoparticles show only one maximum at $471 \mathrm{~cm}^{-1}$ (Figure 2(b)(B)) [21, 42, 43]. These two absorption peaks correlate with the bulk TO-phonon frequency and the LO-phonon frequency [44]. Additional absorption bands at 1590,1415 , and $1340 \mathrm{~cm}^{-1}$ were ascribed to organic impurities originating from reaction intermediates, which can be identified as $\mathrm{Zn}$ hydroxo acetate complex [45] or tetra nuclear oxo zinc acetate cluster $\left(\mathrm{Zn}_{4} \mathrm{O}\left(\mathrm{CH}_{3} \mathrm{COO}\right)_{6}\right)$ $[34,46,47]$, while the one at $3435 \mathrm{~cm}^{-1}$ was assigned to the $\mathrm{OH}$ groups on the surface of $\mathrm{ZnO}$.

The combination of PMMA matrix and $\mathrm{ZnO}$ nanoparticles gives optically transparent materials with high UV absorption [16]. Such materials have high potential in various outdoor applications with high UV light loads. 


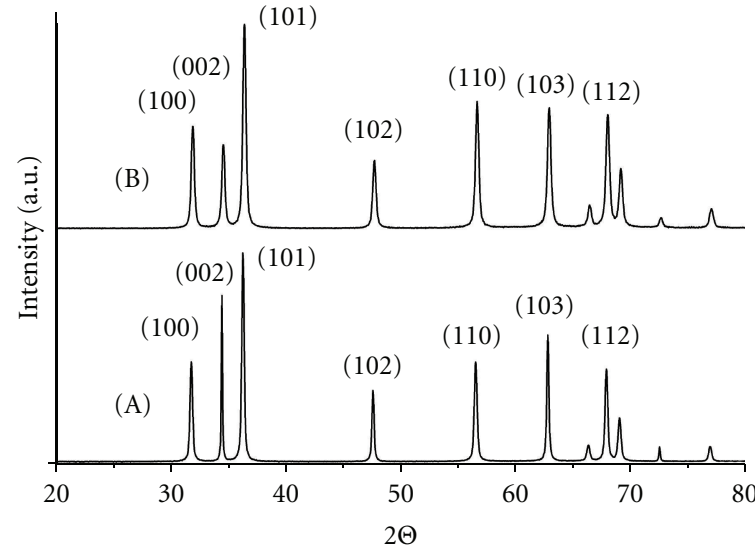

(a)

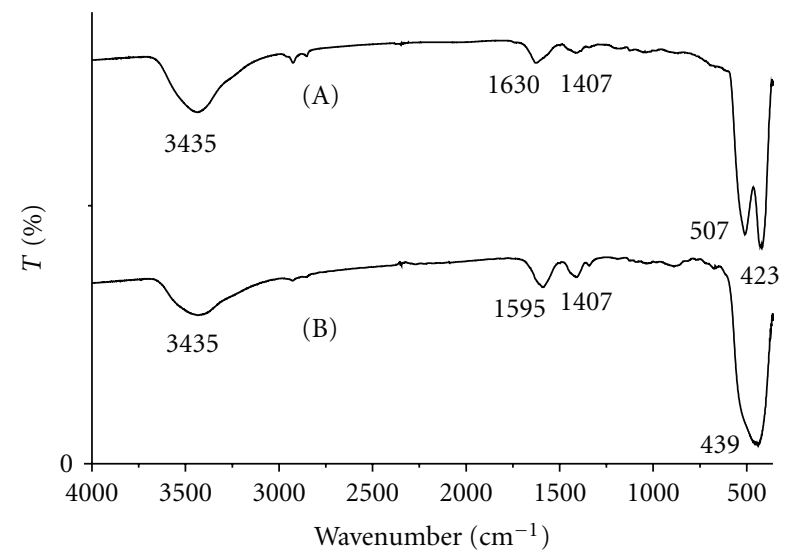

(b)

Figure 2: (a) XRD diffractograms and (b) FTIR spectra of (A) ZnO nanorods and (B) ZnO nanoparticles.

TABLE 1: The length of $\mathrm{ZnO}$ nanowires in correlation with the $\mathrm{p}$ TSA concentration.

\begin{tabular}{lcc}
\hline $\begin{array}{l}\text { Designation } \\
\text { of the sample }\end{array}$ & $\begin{array}{c}\text { Concentration of } \\
\text { p-TSA }(\mathrm{mol} / \mathrm{L})\end{array}$ & $\begin{array}{c}\text { Length of } \mathrm{ZnO} \\
\text { nanorods }(\mathrm{nm})\end{array}$ \\
\hline $\mathrm{ZnO}-1$ & 0.05 & $50-180$ \\
$\mathrm{ZnO}-2$ & 0.1 & $50-150$ \\
$\mathrm{ZnO}-3$ & 0.2 & $30-100$ \\
$\mathrm{ZnO}-4$ & 0.4 & $20-70$ \\
\hline
\end{tabular}

For the preparation of PMMA/ZnO nanocomposites, $\mathrm{ZnO}$ nanorods were first dispersed in MMA which was subsequently polymerized by free-radical chain polymerization of MMA in situ between glass plates starting (a) directly from the $\mathrm{ZnO}$ dispersion in MMA (procedure A), (b) from previously prepared dispersion of $\mathrm{ZnO}$ in prepolymer (procedure B), and (c) the same as in procedure B only with constant sonication during the entire polymerization process (procedure C).

The most important parameter in preparing the homogeneous PMMA/ZnO nanocomposites is dispersion stability of $\mathrm{ZnO}$ particles in MMA monomer. Dispersion stability, that is, $R_{h}$ of $\mathrm{ZnO}$ nanorods in dependence of time and $\mathrm{ZnO}$ concentration (Table 2 ), was studied by dynamic light scattering, DLS. Comparing $R_{h}$ after $10 \mathrm{~min}$ and after $25 \mathrm{~min}$ we observed an increase of $R_{h}$ indicating a slight aggregation of $\mathrm{ZnO}$ nanorods in MMA, but at longer times (45 min) $R_{h}$ no longer increased, indicating that the dispersion became stable. The stability of $\mathrm{ZnO}$ nanorod/MMA dispersion can be explained by the strong interactions between $\mathrm{ZnO}$ surface and carbonyl groups of MMA [48].

When MMA is polymerized by the radical chain mechanism, the weight average molar mass, $M_{w}$, of PMMA reaches values well above $100000 \mathrm{~g} / \mathrm{mol}$ [30] after $45 \mathrm{~min}$ of reaction, and this can explain the stability of dispersion of $\mathrm{ZnO}$ nanorods in the reaction mixture. It has been reported [49] that at isothermal conditions, at temperatures between 70 and $80^{\circ} \mathrm{C}$, bulk radical chain polymerization of
MMA reaches gel effect (Tromsdorff effect) in reaction time between 25 and $50 \mathrm{~min}$. Gel effect raises the viscosity of the system in a few minutes to values above $1 \times 10^{6} \mathrm{Pas}$, and due to the high viscosity of the system $\mathrm{ZnO}$ nanorods remain dispersed in the PMMA matrix.

The distribution of $\mathrm{ZnO}$ nanorods in the PMMA nanocomposites prepared by procedure A was studied by STEM microscopy of their ultra-microtomed sections. STEM micrographs in Figure 3 show cross sections of PMMA/ZnO nanorod composite containing $1 \mathrm{wt} . \%$ of $\mathrm{ZnO}$. The distribution of $\mathrm{ZnO}$ nanorods in PMMA is homogeneous with a few agglomerates. The $\mathrm{ZnO}$ nanorod structure can be observed only for some of the particles because the nanorods are statistically oriented in the three-dimensional space.

Since $\mathrm{ZnO}$ is a highly efficient absorber in the UV region from 32 to $400 \mathrm{~nm}$ due to its wide direct band gap of $3.37 \mathrm{eV}$ [50], the addition of nano- $\mathrm{ZnO}$ into the PMMA matrix significantly enhances UV absorption and UV resistance of nanocomposite materials [51-53]. Transmittances in the $\mathrm{UV}-\mathrm{V}$ is spectral region of PMMA/ZnO nanorod composites, prepared by procedure $\mathrm{A}$, are given in Table 3 . $\mathrm{ZnO}$ nanorods are extremely efficient UV absorbers since they absorb more than $98 \%$ of the incident UV light at concentration of $0.1 \mathrm{wt} . \%$ and higher. Transparency for visible light is poor due to the formation of cavities in the PMMA matrix and due to a certain extent of $\mathrm{ZnO}$ aggregation.

By modifying the MMA polymerization process (procedure B) the transparency of composites for visible light was improved (Figure 4(A)). The prepolymer procedure significantly reduces the shrinking of PMMA and consequently reduces the cavity formation, thus enhancing the visible transparency of nanocomposites [54]. By reducing the concentration of $\mathrm{ZnO}$, the aggregation of $\mathrm{ZnO}$ is substantially reduced and therefore visible transparency has been additionally improved (Figures $4(\mathrm{~B})$ and $4(\mathrm{C})$, while the absorption in the UV region is reduced only at the $\mathrm{ZnO}$ concentration of $0.01 \mathrm{wt} . \%$ (Figure $4(\mathrm{C})$ ).

The modification of nanocomposite preparation procedure by the introduction of the sonication through 


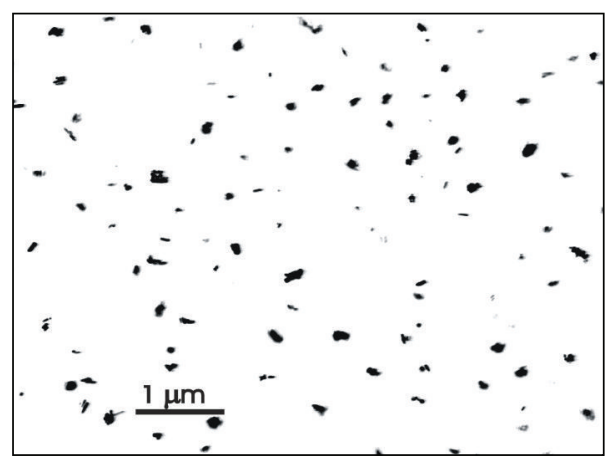

(a)

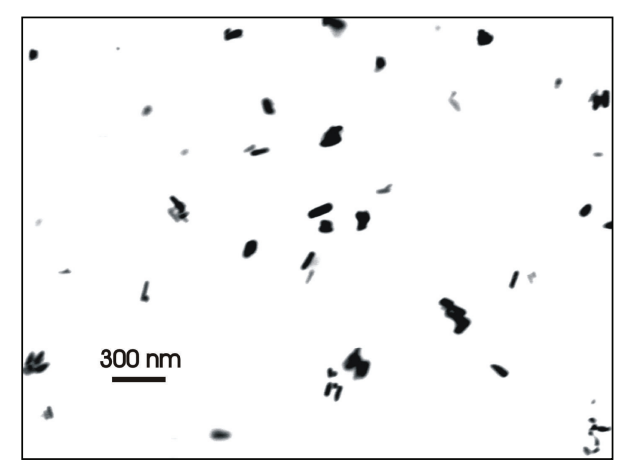

(b)

Figure 3: STEM micrographs of ultramicrotomed sections of PMMA/ZnO nanorod composites ( 1 wt.\% of $\mathrm{ZnO}$ nanorods) at two magnifications: (a) 50000x and (b) 100000x.

TABLE 2: Hydrodynamic radii of $\mathrm{ZnO}$ nanorods in MMA medium in dependence on the concentration and time.

\begin{tabular}{lcccc}
\hline Sample designation & ZnO concentration (wt.\%) & Time $(10 \mathrm{~min})$ & $\begin{array}{c}R_{h}(\mathrm{~nm}) \\
\text { Time }(25 \mathrm{~min})\end{array}$ & 116 \\
\hline $\mathrm{ZnO}$ (nanorod)/MMA & 0.01 & 102 & 198 & 101 \\
$\mathrm{ZnO}$ (nanorod)/MMA & 0.1 & 135 & 198 \\
\hline
\end{tabular}

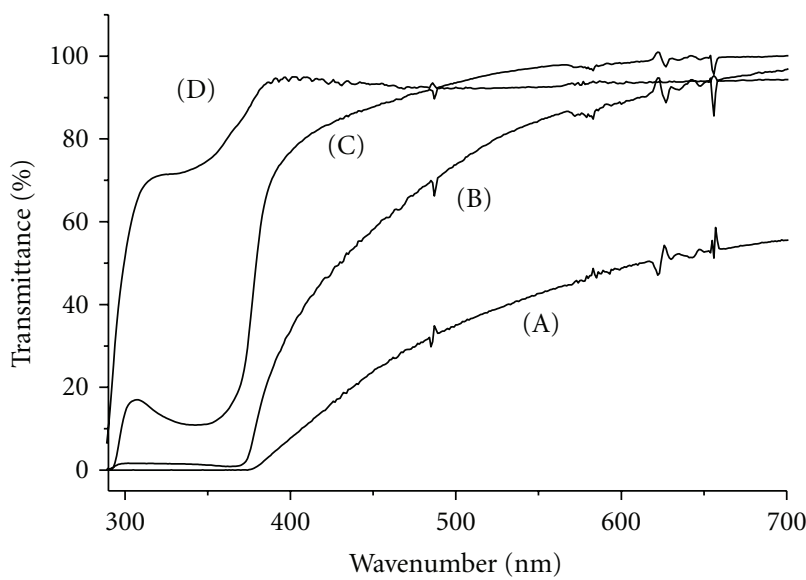

Figure 4: UV-Vis spectra of PMMA/ZnO nanorod composites prepared by procedure $\mathrm{B}$ in dependence on $\mathrm{ZnO}$ concentration: (A) 0.1 wt. $\%$, (B) 0.05 wt. $\%$, (C) 0.01 wt. \%, and (D) PMMA.

the complete prepolymer synthesis (procedure C) additionally reduced $\mathrm{ZnO}$ agglomeration enhancing its visible transparency and significantly increasing the absorption in the UV region (Figure 5(C)).

The influence of the addition of $\mathrm{ZnO}$ nanorods on the mechanical properties of PMMA nanocomposites was studied by dynamic mechanical analysis, DMA. The storage modulus of nanocomposites is decreasing with temperature due to softening, but it increases with the addition of small amounts of $\mathrm{ZnO}$ nanorods (0.01 and $0.1 \mathrm{wt} . \%$ ), while at higher concentrations (1wt.\%) the reinforcing effect is not intensified (Figure 6(a)). This can be explained by the

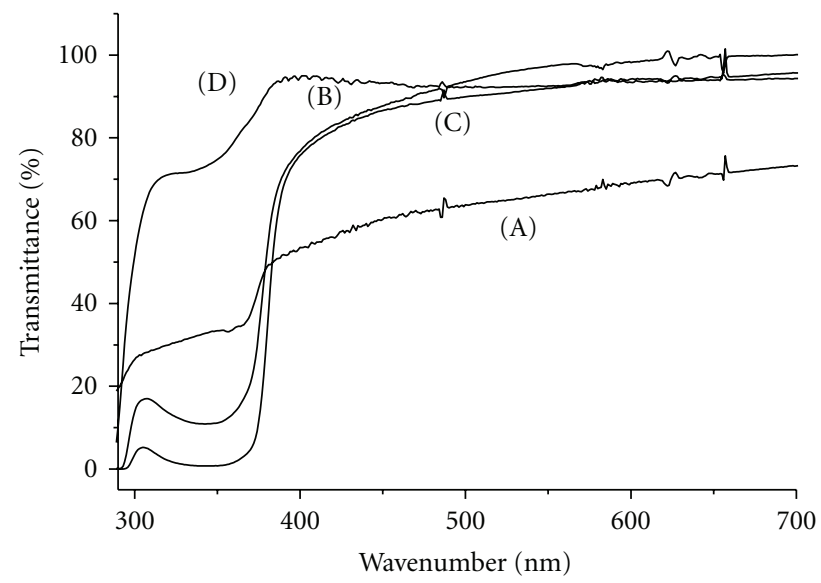

Figure 5: UV-Vis spectra of PMMA/ZnO nanorod composites prepared by different procedures $(\mathrm{ZnO}$ concentration $=0.01 \mathrm{wt} . \%)$ : (A) procedure $A,(B)$ procedure $B,(C)$ procedure $C$, and (D) PMMA.

increased aggregation of $\mathrm{ZnO}$ nanorods at higher concentrations, leading to a decrease of the interfacial surface. Similar effects were observed also by other authors [55]. The increase of the storage modulus in the glassy state (up to $75^{\circ} \mathrm{C}$ ) is approximately $25 \%$, while in the intermediate temperature region (from $75^{\circ} \mathrm{C}$ to $95^{\circ} \mathrm{C}$ ) it is increased by 50 to $100 \%$. Comparison of the storage modulus of PMMA/ZnO nanorods (length $30-150 \mathrm{~nm}$ ) composites with those of PMMA composites with spherical $\mathrm{ZnO}$ nanoparticles (size 20-50 nm, Figure 7(a)) reveals that the latter show a higher increase of the modulus. Therefore $\mathrm{ZnO}$ particle size (specific surface-interface) is a more important factor influencing 
TABLE 3: UV light transmittances of PMMA/ZnO nanorod composites in dependence on the UV wavelength and on the ZnO concentration.

\begin{tabular}{lccccccc}
\hline $\begin{array}{l}\text { Sample } \\
\text { designation }\end{array}$ & $\begin{array}{l}\text { Concentration } \\
\text { of ZnO [\%] }\end{array}$ & 290 & \multicolumn{2}{c}{ Transmittance at various UV wavelengths $(\mathrm{nm})[\%]$} \\
\hline PMMA & - & 10.2 & 300 & 51.5 & 720 & 340 & 360 \\
PMMA/ZnO-1 & 0.01 & 19.4 & 26.5 & 29.9 & 32.6 & 79.0 & 90.8 \\
PMMA/ZnO-2 & 0.1 & 0.16 & 0.14 & 0.17 & 0.042 & 33.9 & 48.8 \\
PMMA/ZnO-3 & 1.0 & 0.19 & 0.20 & 0.31 & 0.072 & 0.17 \\
\hline
\end{tabular}

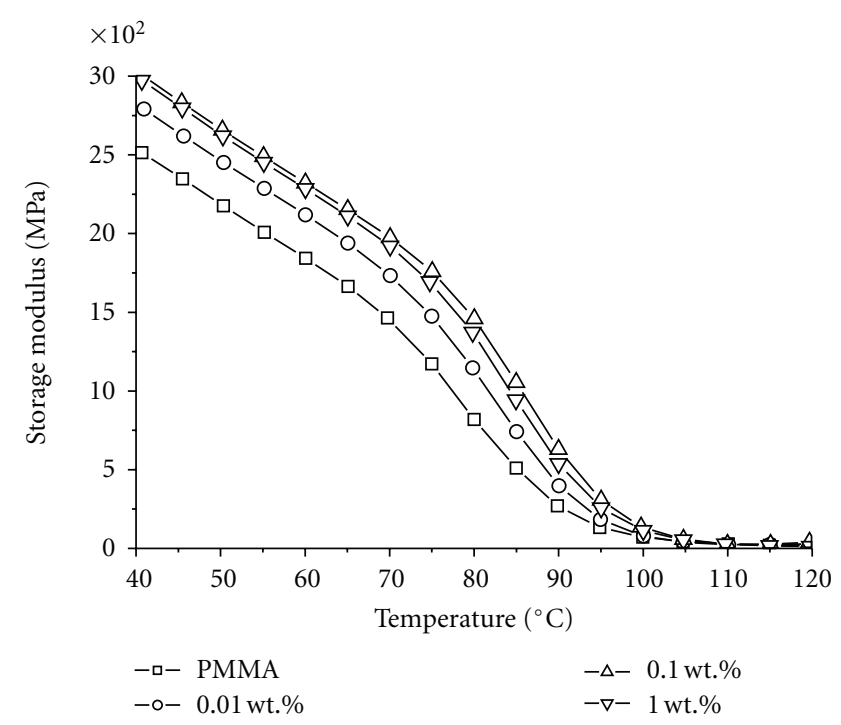

(a)

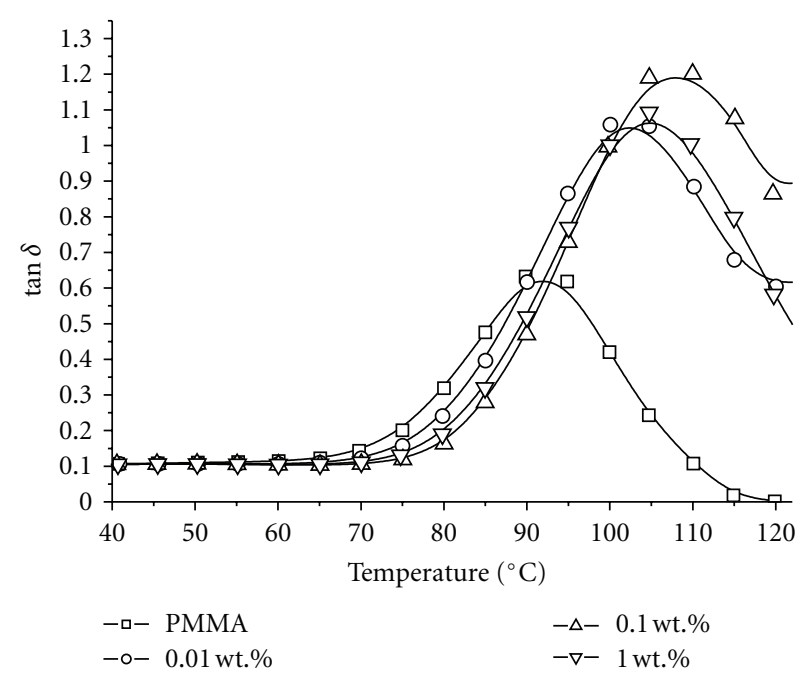

(b)

Figure 6: Storage modulus (a) and $\tan \delta$ (b) of PMMA/ZnO nanorod composites as a function of the $\mathrm{ZnO}$ nanorods concentration.

the storage modulus of PMMA/ZnO nanocomposites than is the shape (length) of the particle.

Figure 6(b) shows the dependence of $\tan \delta$ on the concentration of $\mathrm{ZnO}$ nanorods as a function of temperature showing relaxation peaks corresponding to glass transition of the amorphous phase. The dependence reveals that

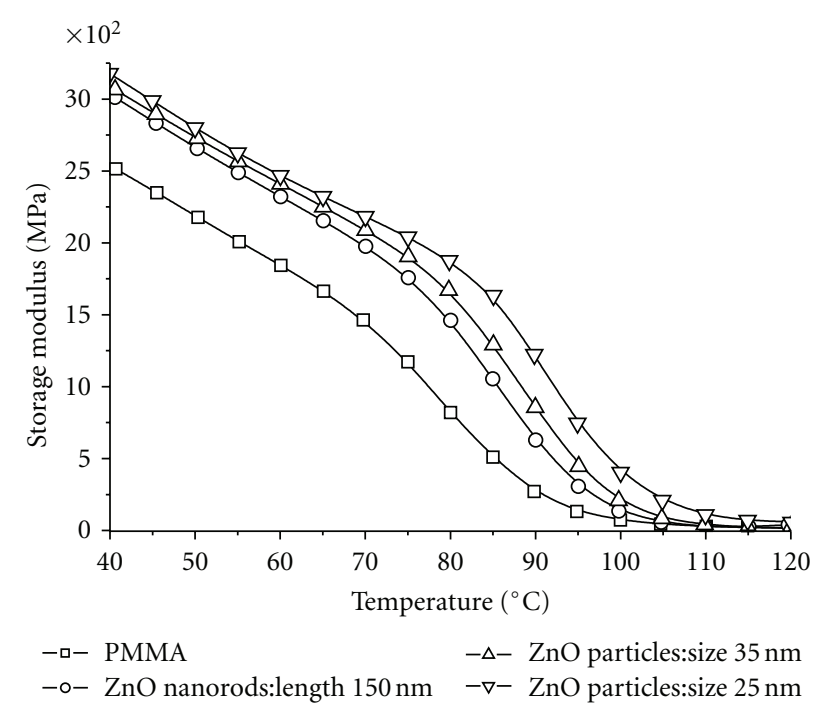

(a)

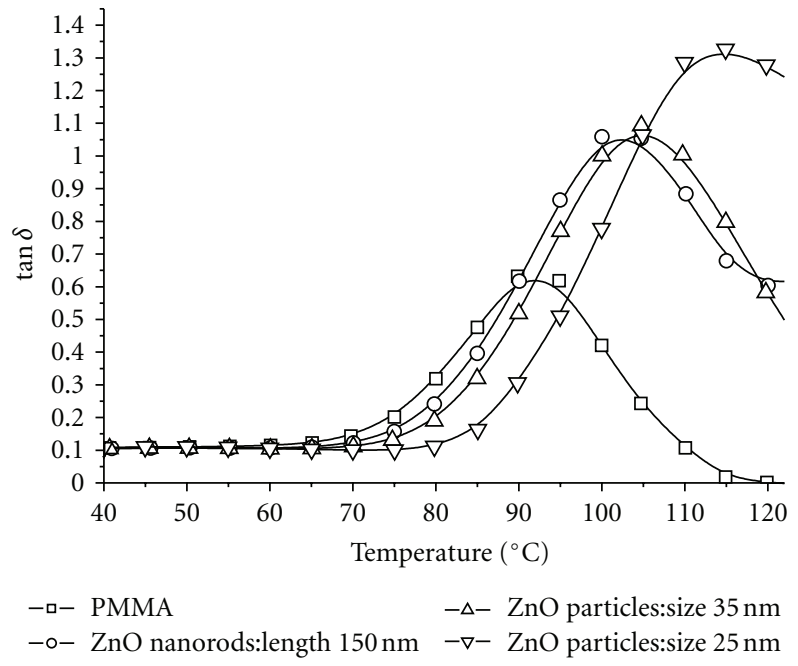

(b)

Figure 7: Storage modulus (a) and $\tan \delta$ (b) of PMMA/ZnO nanorod composites as a function of the $\mathrm{ZnO}$ particle size and shape-concentration of $\mathrm{ZnO}$ is $0.1 \mathrm{wt} . \%$.

glass transition is shifted to higher temperatures when a low concentration of $\mathrm{ZnO}$ nanorods is added ( 0.01 and $0.1 \mathrm{wt} . \%)$, while at higher concentrations no additional shift was observed which is consistent with the results in Figure 6(a). It is interesting that the shift of glass transition temperature to higher temperatures (Figures 6(b) and 7(b)) 


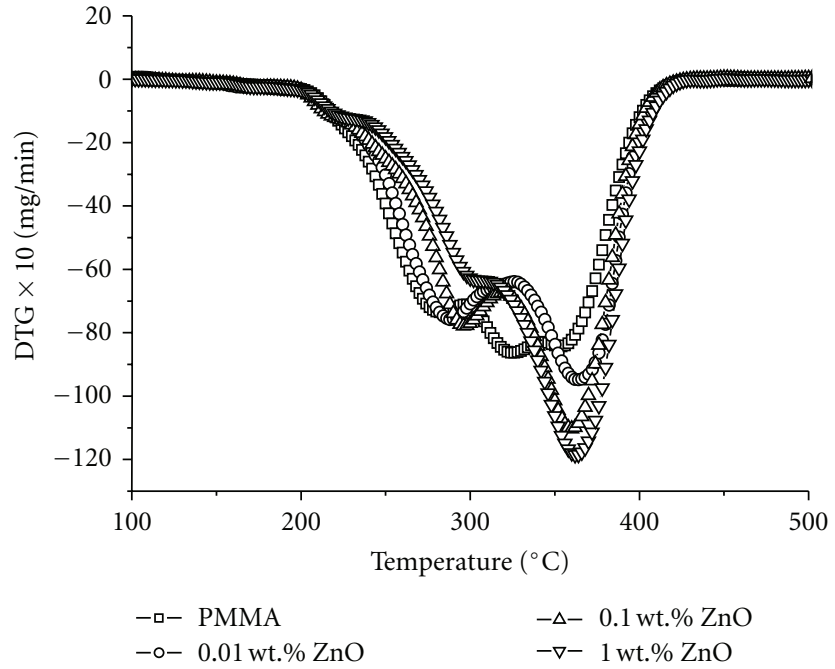

FIGURE 8: DTG curves of degradation of PMMA/ZnO nanorod composites in dependence on $\mathrm{ZnO}$ concentration.

and the increase of storage modulus (Figures 6(a) and 7(a)) both show similar trends. In the temperature region above $85^{\circ} \mathrm{C}, \tan \delta$ of these materials is above 0.3 meaning that they are good damping materials [55].

$\mathrm{ZnO}$ nanoparticles can substantially enhance the thermal stability of PMMA chains, when MMA is polymerized in their presence [56-58]. DTG decomposition curves of PMMA/ZnO nanorod composites in dependence of $\mathrm{ZnO}$ concentration are shown in Figure 8. The DTG curve of pure PMMA (Figure 8) shows three degradation peaks at $270^{\circ} \mathrm{C}$ (scission of head to head linkages), at $330^{\circ} \mathrm{C}$ (scission of vinylidene double bonds), and at $370^{\circ} \mathrm{C}$ (random scission of PMMA chain) [59]. DTG curves of PMMA/ZnO nanorod composites (Figure 8) show less intense peaks of head to head linkage decomposition and of vinylidene double-bond scission at 270 and $330^{\circ} \mathrm{C}$, respectively, while the peak of random scission at $370^{\circ} \mathrm{C}$ becomes much more intense. This indicates that $\mathrm{ZnO}$ nanorods thermally stabilize the PMMA matrix in concentration of $1 \mathrm{wt} . \%$ and higher. Compared to spherical $\mathrm{ZnO}$ nanoparticles their thermal stabilization is less intense. It is interesting to note that thermal stabilization of PMMA is observed only when MMA is polymerized in the presence of nano- $\mathrm{ZnO}$, while nano- $\mathrm{ZnO}$ admixed to the PMMA has no influence on the thermal properties of nanocomposite [57]. The absence of a vinylidene double-bond scission peak in DTG curves at $\mathrm{ZnO}$ concentrations of $1 \mathrm{wt} . \%$ and above suggests that nano- $\mathrm{ZnO}$ reduces the double-bond concentration in PMMA chains [57]. The reduced concentration of vinylidene double bonds with increasing $\mathrm{ZnO}$ concentration was confirmed by ${ }^{1} \mathrm{H}$ NMR spectroscopy [30].

\section{Conclusions}

$\mathrm{ZnO}$ nanorods with organophilic surface were synthesized by hydrolysis of Zinc(II) acetate in DEG medium with the addition of p-TSA as an end-capping agent. p-TSA reduces the average particle size, increases the $\mathrm{ZnO}$ crystallinity, and influences the preferential growth of $\mathrm{ZnO}$ in c-axis as shown by the electron microscopy. $\mathrm{ZnO}$ nanorods have been synthesized at high concentration of the precursor (1 M), thus allowing their preparation in gram quantities which is beneficial in the preparation of composites.

$\mathrm{ZnO}$ nanorods form stable dispersions in MMA for at least $45 \mathrm{~min}$ at concentrations of $0.1 \mathrm{wt} . \%$ and below. During the radical chain polymerization of MMA, the system reaches gel effect in the reaction time of 20 to $50 \mathrm{~min}$ at temperatures between 70 and $80^{\circ} \mathrm{C}$. Due to the high viscosity (above $1 \times 10^{6} \mathrm{Pas}$ ) of the PMMA/ZnO dispersion, $\mathrm{ZnO}$ nanorods remain dispersed in the PMMA matrix.

$\mathrm{ZnO}$ nanorods are excellent UV absorbers because they quantitatively absorb UV light in the 290 to $370 \mathrm{~nm}$ region at concentrations of $0.1 \mathrm{wt} . \%$ of $\mathrm{ZnO}$ and above. PMMA plates with high visible light transparency and high UV absorption were prepared using the prepolymer procedure (procedure $\mathrm{C})$. The optimal concentration of $\mathrm{ZnO}$ nanorods is between 0.01 and 0.1 wt. $\%$ to obtain materials with high absorption of UV light and high transparency for visible light.

DMA analysis of PMMA/ZnO nanorods composites shows that $\mathrm{ZnO}$ nanorods increase the storage modulus of nanocomposites and shift the $T_{g}$ towards higher temperatures at low concentrations (0.01-0.1 wt.\%), while at higher concentrations (1.0wt.\%) the reinforcing effect is deteriorated, which was ascribed to the aggregation of $\mathrm{ZnO}$ nanorods. Comparing the reinforcing effects of $\mathrm{ZnO}$ nanorods and $\mathrm{ZnO}$ nanoparticles it was observed that the latter show a more pronounced effect on the storage modulus and $T_{g}$ than the former, due to their smaller size and larger specific surface.

$\mathrm{ZnO}$ nanorods enhance the thermal stability of PMMA at concentrations of $1 \mathrm{wt} . \%$ and above. The thermal degradation of PMMA is shifted towards higher temperatures by $20-40^{\circ} \mathrm{C}$, which was ascribed to the reduced concentration of vinylidene chain end double bonds as indicated by the changes of DTG curves.

\section{Acknowledgments}

The authors acknowledge the financial support from the Ministry of Higher Education, Science and Technology of the Republic of Slovenia through contract no. 3211-10000057 (Center of Excellence for Polymer Materials and Technologies, PoliMaT). The authors also thank Miroslav Huskić, Ph.D., of the National Institute of Chemistry for the DMA measurements, and Igor Djerdj, Ph.D., of the Rudjer Bošković Institute, Zagreb, Croatia, for HR-TEM microscopy.

\section{References}

[1] G. Shen, P. C. Chen, K. Ryu, and C. Zhou, "Devices and chemical sensing applications of metal oxide nanowires," Journal of Materials Chemistry, vol. 19, no. 7, pp. 828-839, 2009.

[2] J. P. Cheng, X. B. Zhang, X. Y. Tao, H. M. Lu, Z. Q. Luo, and F. Liu, "Fine-tuning the synthesis of $\mathrm{ZnO}$ nanostructures by an alcohol thermal process," Journal of Physical Chemistry B, vol. 110, no. 21, pp. 10348-10353, 2006. 
[3] C. C. Lin, W. S. Lee, C. C. Sun, and W. H. Whu, "A varistor-polymer composite with nonlinear electrical-thermal switching properties," Ceramics International, vol. 34 , no. 1, pp. 131-136, 2008.

[4] D. A. Schwartz, N. S. Norberg, Q. P. Nguyen, J. M. Parker, and D. R. Gamelin, "Magnetic quantum dots: synthesis, spectroscopy, and magnetism of $\mathrm{Co}^{2+}$ - and $\mathrm{Ni}^{2+}$-doped $\mathrm{ZnO}$ nanocrystals," Journal of the American Chemical Society, vol. 125, no. 43, pp. 13205-13218, 2003.

[5] W. I. Park, C. H. Lee, J. H. Chae, D. H. Lee, and G. C. Yi, "Ultrafine $\mathrm{ZnO}$ nanowire electronic device arrays fabricated by selective metal-organic chemical vapor deposition," Small, vol. 5, no. 2, pp. 181-184, 2009.

[6] D. Kabra, M. H. Song, B. Wenger, R. H. Friend, and H. J. Snaith, "High efficiency composite metal oxide-polymer electroluminescent devices: a morphological and material based investigation," Advanced Materials, vol. 20, no. 18, pp. 3447-3452, 2008.

[7] C. S. Rout, A. R. Raju, A. Govindaraj, and C. N. R. Rao, "Ethanol and hydrogen sensors based on $\mathrm{ZnO}$ nanoparticles and nanowires," Journal of Nanoscience and Nanotechnology, vol. 7, no. 6, pp. 1923-1929, 2007.

[8] A. M. Peiró, P. Ravirajan, K. Govender et al., "Hybrid polymer/metal oxide solar cells based on $\mathrm{ZnO}$ columnar structures," Journal of Materials Chemistry, vol. 16, no. 21, pp. 2088-2096, 2006.

[9] R. Jose, V. Thavasi, and S. Ramakrishna, "Metal oxides for dyesensitized solar cells," Journal of the American Ceramic Society, vol. 92, no. 2, pp. 289-301, 2009.

[10] M. H. Huang, S. Mao, H. Feick et al., "Room-temperature ultraviolet nanowire nanolasers," Science, vol. 292, no. 5523, pp. 1897-1899, 2001.

[11] D. P. Liu, G. D. Li, Y. Su, and J. S. Chen, "Highly luminescent $\mathrm{ZnO}$ nanocrystals stabilized by ionic-liquid components," Angewandte Chemie, vol. 45, no. 44, pp. 7370-7373, 2006.

[12] Y. Hu, Z. Jiang, C. Xu, M. Ting, G. Jun, and W. Tim, "Monodisperse $\mathrm{ZnO}$ nanodots: synthesis, charaterization, and optoelectronic properties," Journal of Physical Chemistry C, vol. 111, no. 27, pp. 9757-9760, 2007.

[13] A. J. Hoffman, H. Yee, G. Mills, and M. R. Hoffmann, "Photoinitiated polymerization of methyl methacrylate using Q-sized ZnO colloids," Journal of Physical Chemistry, vol. 96, no. 13, pp. 5540-5546, 1992.

[14] J. P. Cheng, X. B. Zhang, X. Y. Tao, H. M. Lu, Z. Q. Luo, and F. Liu, "Fine-tuning the synthesis of $\mathrm{ZnO}$ nanostructures by an alcohol thermal process," Journal of Physical Chemistry B, vol. 110, no. 21, pp. 10348-10353, 2006.

[15] R. Wahab, S. G. Ansari, Y. S. Kim, M. Song, and H. S. Shin, "The role of $\mathrm{pH}$ variation on the growth of zinc oxide nanostructures," Applied Surface Science, vol. 255, no. 9, pp. 4891-4896, 2009.

[16] J. Zhang, L. Sun, J. Yin, H. Su, C. Liao, and C. Yan, "Control of $\mathrm{ZnO}$ morphology via a simple solution route," Chemistry of Materials, vol. 14, no. 10, pp. 4172-4177, 2002.

[17] S. K. N. Ayudhya, P. Tonto, O. Mekasuwandumrong, V. Pavarajarn, and P. Praserthdam, "Solvothermal synthesis of $\mathrm{ZnO}$ with various aspect ratios using organic solvents," Crystal Growth and Design, vol. 6, no. 11, pp. 2446-2450, 2006.

[18] M. Bitenc, P. Podbršček, Z. C. Orel et al., "Correlation between morphology and defect luminescence in precipitated $\mathrm{ZnO}$ nanorod powders," Crystal Growth and Design, vol. 9, no. 2, pp. 997-1001, 2009.
[19] Z. R. R. Tian, J. A. Voigt, J. Liu et al., "Complex and oriented $\mathrm{ZnO}$ nanostructures," Nature Materials, vol. 2, no. 12, pp. 821826, 2003.

[20] Y. W. Heo, D. P. Norton, L. C. Tien et al., "ZnO nanowire growth and devices," Materials Science and Engineering R, vol. 47, no. 1-2, pp. 1-47, 2004.

[21] H. Kleinwechter, C. Janzen, J. Knipping, H. Wiggers, and P. Roth, "Formation and properties of $\mathrm{ZnO}$ nano-particles from gas phase synthesis processes," Journal of Materials Science, vol. 37, no. 20, pp. 4349-4360, 2002.

[22] D.-H. Kuo and B.-J. Chang, "Growth behaviors of $\mathrm{ZnO}$ nanorods grown with the $\mathrm{Sn}$-based bilayer catalyst-covered substrates," Journal of Nanomaterials, vol. 2011, Article ID 603098, 2011.

[23] P. Tonto, O. Mekasuwandumrong, S. Phatanasri, V. Pavarajarn, and P. Praserthdam, "Preparation of $\mathrm{ZnO}$ nanorod by solvothermal reaction of zinc acetate in various alcohols," Ceramics International, vol. 34, no. 1, pp. 57-62, 2008.

[24] C. Pacholski, A. Kornowski, and H. Weller, "Self-assembly of $\mathrm{ZnO}$ : from nanodots, to nanorods," Angewandte Chemie International Edition, vol. 40, no. 7, pp. 1188-1191, 2002.

[25] D. Jezequel, J. Guenot, N. Jouini, and F. Fievet, "Submicrometer zinc oxide particles: elaboration in polyol medium and morphological characteristics," Journal of Materials Research, vol. 10, no. 1, pp. 77-83, 1995.

[26] E. W. Seelig, B. Tang, A. Yamilov, H. Cao, and R. P. H. Chang, "Self-assembled 3D photonic crystals from $\mathrm{ZnO}$ colloidal spheres," Materials Chemistry and Physics, vol. 80, no. 1, pp. 257-263, 2003.

[27] L. Poul, S. Ammar, N. Jouini, F. Fievet, and F. Villain, "Synthesis of inorganic compounds (metal, oxide and hydroxide) in polyol medium: a versatile route related to the sol-gel process," Journal of Sol-Gel Science and Technology, vol. 26, no. 1-3, pp. 261-265, 2003.

[28] A. Anžlovar, Z. C. Orel, and M. Žigon, "Copper(I) oxide and metallic copper particles formed in 1,2-propane diol," Journal of the European Ceramic Society, vol. 27, no. 2-3, pp. 987-991, 2007.

[29] A. Anžlovar, Z. C. Orel, and M. Žigon, "Morphology and particle size of di(ethylene glycol) mediated metallic copper nanoparticles," Journal of Nanoscience and Nanotechnology, vol. 8, no. 7, pp. 3516-3525, 2008.

[30] A. Anžlovar, Z. Crnjak Orel, and M. Žigon, "Poly(methyl methacrylate) composites prepared by in situ polymerization using organophillic nano-to-submicrometer zinc oxide particles," European Polymer Journal, vol. 46, no. 6, pp. 1216-1224, 2010.

[31] M. M. Demir, M. Memesa, P. Castignolles, and G. Wegner, "PMMA/zinc oxide nanocomposites prepared by in-situ bulk polymerization," Macromolecular Rapid Communications, vol. 27, no. 10, pp. 763-770, 2006.

[32] S. Li, M. S. Toprak, Y. S. Jo, J. Dobson, D. K. Kim, and M. Muhammed, "Bulk synthesis of transparent and homogeneous polymeric hybrid materials with $\mathrm{ZnO}$ quantum dots and PMMA," Advanced Materials, vol. 19, no. 24, pp. 43474352, 2007.

[33] P. Podbršček, G. Dražić, A. Anžlovar, and Z. C. Orel, “The preparation of zinc silicate/ $\mathrm{ZnO}$ particles and their use as an efficient UV absorber," Materials Research Bulletin, vol. 46, no. 11, pp. 2105-2111, 2011.

[34] A. Anžlovar, K. Kogej, Z. Crnjak Orel, and M. Žigon, "Polyol mediated nano size zinc oxide and nanocomposites with 
poly(methyl methacrylate)," Express Polymer Letters, vol. 5, no. 7, pp. 604-619, 2011.

[35] R. B. Heller, J. McGannon, and A. H. Weber, "Precision determination of the lattice constants of zinc oxide," Journal of Applied Physics, vol. 21, no. 12, pp. 1283-1284, 1950.

[36] A. Sinha and B. P. Sharma, "Preparation of copper powder by glycerol process," Materials Research Bulletin, vol. 37, no. 3, pp. 407-416, 2002.

[37] S. F. Wang, T. Y. Tseng, Y. R. Wang, C. Y. Wang, and H. C. Lu, "Effect of $\mathrm{ZnO}$ seed layers on the solution chemical growth of ZnO nanorod arrays," Ceramics International, vol. 35, no. 3, pp. 1255-1260, 2009.

[38] T. Alammar and A. V. Mudring, "Facile ultrasound-assisted synthesis of $\mathrm{ZnO}$ nanorods in an ionic liquid," Materials Letters, vol. 63, no. 9-10, pp. 732-735, 2009.

[39] W. J. Li, E. W. Shi, W. Z. Zhong, and Z. W. Yin, "Growth mechanism and growth habit of oxide crystals," Journal of Crystal Growth, vol. 203, no. 1, pp. 186-196, 1999.

[40] A. Dakhlaoui, M. Jendoubi, L. S. Smiri, A. Kanaev, and N. Jouini, "Synthesis, characterization and optical properties of $\mathrm{ZnO}$ nanoparticles with controlled size and morphology," Journal of Crystal Growth, vol. 311, no. 16, pp. 3989-3996, 2009.

[41] S. Hayashi, N. Nakamori, and H. Kanamori, "Generalized theory of average dielectric constant and its application to infrared absorption by $\mathrm{ZnO}$ small particles," Journal of the Physical Society of Japan, vol. 46, no. 1, pp. 176-183, 1979.

[42] L. Wu, Y. Wu, X. Pan, and F. Kong, "Synthesis of ZnO nanorod and the annealing effect on its photoluminescence property," Optical Materials, vol. 28, no. 4, pp. 418-422, 2006.

[43] Z. Yang and Q. H. Liu, "The structural and optical properties of $\mathrm{ZnO}$ nanorods via citric acid-assisted annealing route," Journal of Materials Science, vol. 43, no. 19, pp. 6527-6530, 2008.

[44] Z. Yang, X. Zong, Z. Ye, B. Zhao, Q. Wang, and P. Wang, “The application of complex multiple forklike $\mathrm{ZnO}$ nanostructures to rapid and ultrahigh sensitive hydrogen peroxide biosensors," Biomaterials, vol. 31, no. 29, pp. 7534-7541, 2010.

[45] L. Znaidi, G. J. A. A. Soler Illia, S. Benyahia, C. Sanchez, and A. V. Kanaev, "Oriented $\mathrm{ZnO}$ thin films synthesis by sol-gel process for laser application," Thin Solid Films, vol. 428, no. 1-2, pp. 257-262, 2003.

[46] M. K. Johnson, D. B. Powell, and R. D. Cannon, "Vibrational spectra of carboxylato complexes-I. Infrared and Raman spectra of beryllium(II) acetate and formate and of zinc(II) acetate and zinc(II) acetate dihydrate," Spectrochimica Acta A, vol. 37, no. 10, pp. 899-904, 1981.

[47] M. K. Johnson, D. B. Powell, and R. D. Cannon, "Vibrational spectra of carboxylato complexes-II. Some oxo-tetranuclear complexes," Spectrochimica Acta A, vol. 38, no. 2, pp. 125-131, 1982.

[48] V. D. Koshevar, "The influence of poly(methyl methacrylate) on the stability of zinc oxide dispersions in nonaqueous media of various acidity," Colloid journal of the Russian Academy of Sciences, vol. 57, no. 5, pp. 649-652, 1995.

[49] J. S. Sangwai, D. N. Saraf, and S. K. Gupta, "Viscosity of bulk free radical polymerizing systems under near-isothermal and non-isothermal conditions," Polymer, vol. 47, no. 9, pp. 30283035, 2006.

[50] H. Miyazaki, Y. Teranishi, and T. Ota, "Fabrication of uvopaque and visible-transparent composite film," Solar Energy Materials and Solar Cells, vol. 90, no. 16, pp. 2640-2646, 2006.
[51] G. Kickelbick, "Concepts for the incorporation of inorganic building blocks into organic polymers on a nanoscale," Progress in Polymer Science, vol. 28, no. 1, pp. 83-114, 2003.

[52] H. Y. Yu, J. Du, J. S. Gu et al., "Chemical modification on the surface of nano-particles of $\mathrm{ZnO}$ and its characterization," Spectroscopy and Spectral Analysis, vol. 24, no. 2, pp. 177-179, 2004.

[53] D. Sun, N. Miyatake, and H. J. Sue, "Transparent PMMA/ZnO nanocomposite films based on colloidal $\mathrm{ZnO}$ quantum dots," Nanotechnology, vol. 18, no. 21, Article ID 215606, 2007.

[54] B. R. Kine, R. W. Novak, and M. Grayson, "Methacrylic polymers," in Kirk-Othmer Encycopedia of Chemical Technology, vol. 15, p. 377, Wiley-Interscience, New York, NY, USA, 3rd edition, 1981.

[55] M. Agrawal, S. Gupta, N. E. Zafeiropoulos, U. Oertel, R. Häßler, and M. Stamm, "Nano-level mixing of $\mathrm{ZnO}$ into poly(Methyl methacrylate)," Macromolecular Chemistry and Physics, vol. 211, no. 17, pp. 1925-1932, 2010.

[56] V. Khrenov, F. Schwager, M. Klapper, M. Koch, and K. Müllen, "Compatibilization of inorganic particles for polymeric nanocomposites. Optimization of the size and the compatibility of ZnO particles," Polymer Bulletin, vol. 58, no. 5-6, pp. 799-807, 2007.

[57] M. M. Demir, P. Castignolles, U. Akbey, and G. Wegner, "Insitu bulk polymerization of dilute particle/MMA dispersions," Macromolecules, vol. 40, no. 12, pp. 4190-4198, 2007.

[58] Y. Ding, Z. Gui, J. Zhu, Z. Wang, Y. Hu, and L. Song, "Poly(methyl methacrylate)-nanoribbon nanocomposites with high thermal stability and improvement in the glasstransition temperature," Journal of Materials Research, vol. 22, no. 12, pp. 3316-3323, 2007.

[59] T. Kashiwagi, A. Inaba, J. E. Brown, K. Hatada, T. Kitayama, and E. Masuda, "Effects of weak linkages on the thermal and oxidative degradation of poly(methyl methacrylates)," Macromolecules, vol. 19, no. 8, pp. 2160-2168, 1986. 

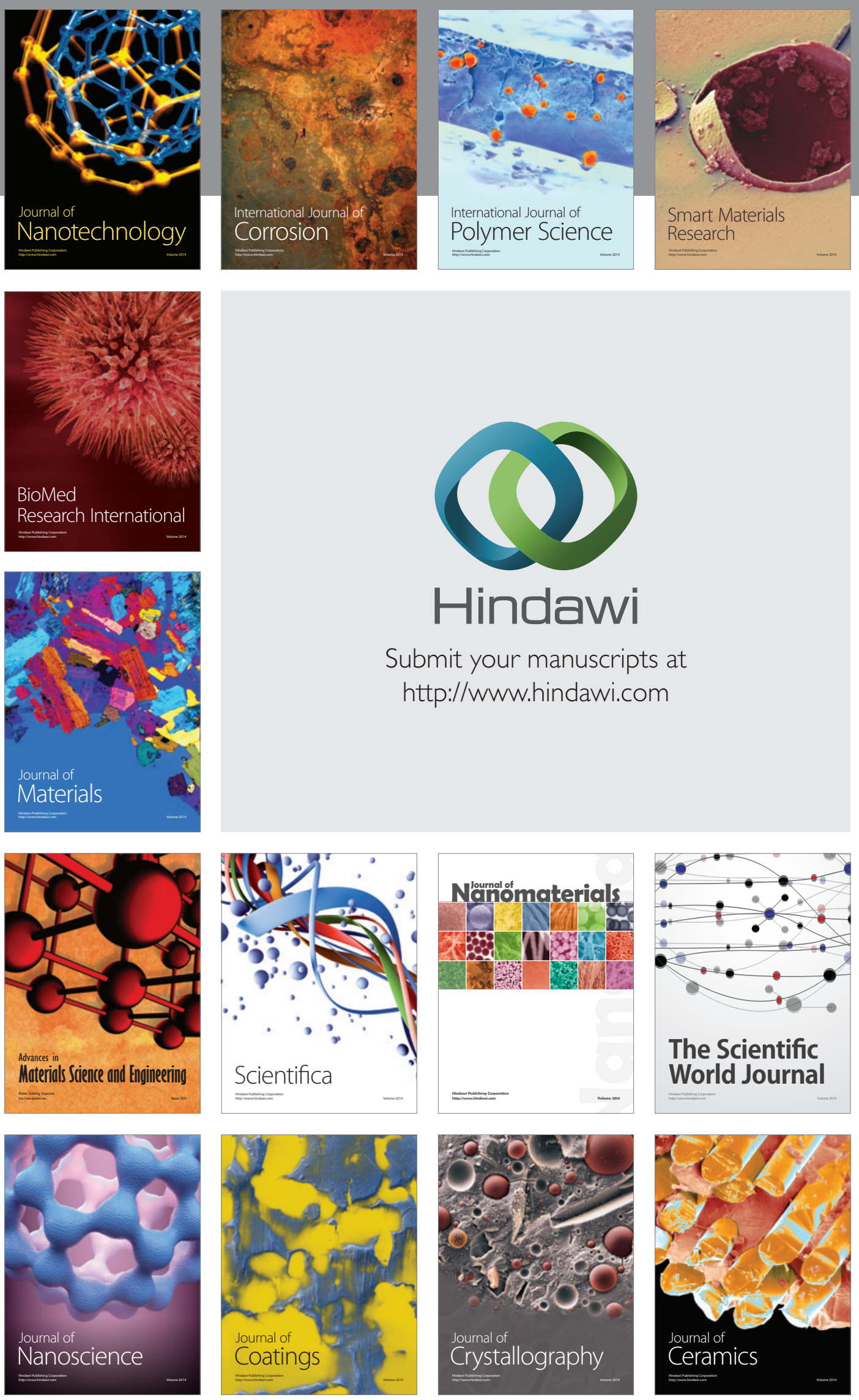

The Scientific World Journal

Submit your manuscripts at

http://www.hindawi.com

\section{World Journal}

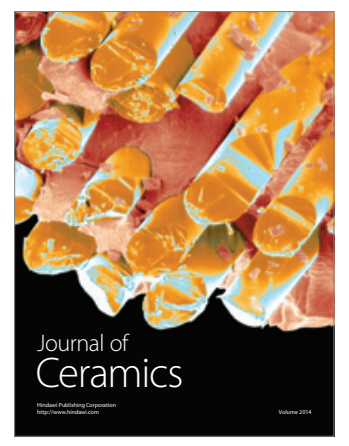

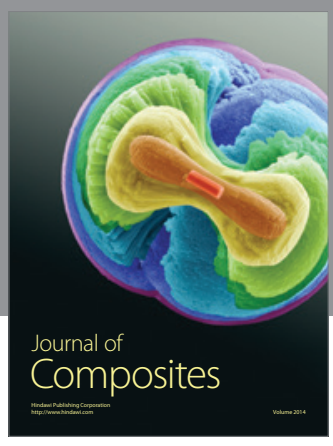
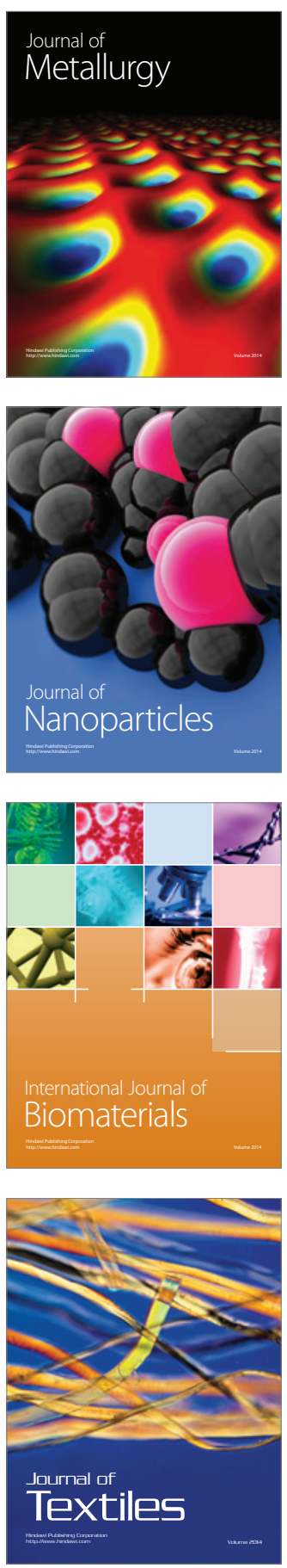